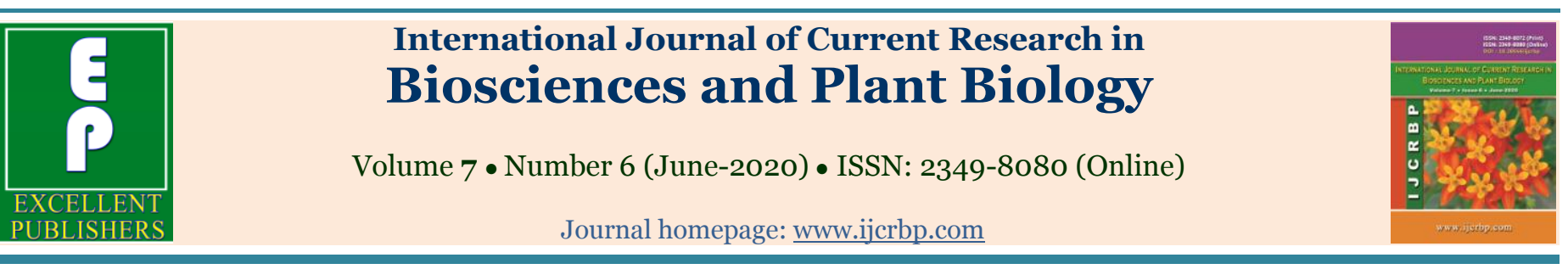

\title{
Chemical constituents of olive oil commonly sold in Wukari, Nigeria
}

\author{
Chinedu Imo* \\ Department of Biochemistry, Faculty of Pure and Applied Sciences, Federal University Wukari, \\ P.M.B. 1020, Wukari, Taraba State, Nigeria \\ ${ }^{*}$ Corresponding author; e-mail: chineduo4@yahoo.com; Telephone: +234-8037505543
}

\begin{tabular}{|c|c|}
\hline Article Info & \multirow{5}{*}{$\begin{array}{l}\text { The chemical constituents of olive oil commonly sold in Wukari, Nigeria were evaluated } \\
\text { in this study. Olive oil is commonly used in nutrition, medicine and industries for } \\
\text { various purposes. The chemical constituents of olive oil were analyzed using GC (model } \\
\text { No. 7890B) and MS detector (model 5977A). Several constituents with various } \\
\text { functions were detected in olive oil. Squalene was the most abundant constituent } \\
\text { detected in highest amount in the olive oil. It constitutes about } 99.56 \% \text { of the total } \\
\text { constituents detected. Some of the chemical constituents detected in olive oil has been } \\
\text { reported and documented to be used for various purposes, including nutritional, } \\
\text { medicinal, pharmaceutical and industrial. Due to the constituents present in olive oil, it } \\
\text { is recommended for nutritional, pharmaceutical and medicinal purposes. }\end{array}$} \\
\hline $\begin{array}{l}\text { Date of Acceptance: } \\
25 \text { May } 2020\end{array}$ & \\
\hline & \\
\hline Keywords & \\
\hline & \\
\hline
\end{tabular}

Olive oil

Squalene

\section{Introduction}

Olive oil is the fruit juice of the tree Olea europaea. Olive oil which is often with a delicate and unique flavour is obtained when the olive fruits are harvested at their optimal maturity stage and are properly processed. There are different cultivars of olive and some olive cultivars produce oil that has better flavour quality than others (Kiritsakis, 1998). Kiritsakis (1998) documented that olive cultivar, origin, storage conditions of fruit, maturity stage of fruit, and olive fruit processing influences the flavour, aroma and taste components of olive oil. Also, there is a good correlation between the flavour and aroma of olive oil and its polyphenol content.
The unique flavour and nutritional value of olive oil contributes to its increase in consumption internationally. The nutritional value of olive oil is believed to be mainly due to its high monounsaturation (oleic is the main fatty acid of olive oil) and to the presence of phenols, tocopherols, squalene, and flavour components (Fedeli, 1993). Also, the unique flavour and aroma of olive oil are reported to be generated by a number of constituents which are present at very low concentrations (Fedeli, 1977). These constituents are closely related to a group of substances which is known as minor polar components with antioxidative properties (Fedeli, 1993). The presence of flavour components in olive 
oil has been reported to be related to many factors (Inglese, 1994; Ranalli and Ferante, 1996), since different cultivars of olive fruit may produce oils of different flavour compounds and therefore different sensory characteristics under identical conditions of environment and cultivation.

Olive oil is well known for its health benefits and diet patterns with higher intakes of olive oil are associated with a reduced risk of death from all causes (Sala-Vila et al., 2016). Although higher consumption of fruits, legumes and vegetables are beneficial to health and could provide protection from cardiovascular diseases, olive oil is independently protective (Grosso et al., 2015). Olive oil has been reported to possess some properties which enables it to play certain roles such as in the prevention (Lopez et al., 2016) and treatment of hypertension (Fito et al., 2005). According to Fito et al. (2005), virgin and refined olive oil (about 3 tablespoons per day) were compared in men that had coronary heart disease. The findings showed that consuming virgin olive oil rich in phenolic compounds was shown to possess antioxidant properties and was able to reduce blood pressure in these patients. According to some studies, the consumption of olive oil may help prevent type 2 diabetes (Guasch-Ferre 2015; Storniolo et al., 2015). Also, the provision of extravirgin olive oil to adults with high risk of cardiovascular disease reduced the risk of type 2 diabetes by $40 \%$ in only 4 years (Storniolo et al., 2015).

There are some scientific evidences to support a link between olive oil intake and cancer prevention (Psaltopoulou et al., 2011). Specifically, people with the highest intake of olive oil have less risk of any type of cancer compared to those with the lowest intake. It has been reported that consumption of olive oil may also decrease the risk of breast cancer (Xin et al., 2015) and cancers of the digestive system (Psaltopoulou et al., 2011).

Currently, olive oil is used for various reasons in households. Apart from its use in nutrition, some people use it for medicinal purposes, including in traditional medicine, while others believe and use it as antidote for poison. In many parts of the world, olive oil is commonly used for religious purposes, especially, by the Christian folks. Due to its wide use and application in many parts of the world, there is need to evaluate the chemical constituents of olive oil as commonly sold in the market.

\section{Materials and methods}

\section{Chemical substance used}

Olive oil used in this study was purchased as commonly sold in a pharmaceutical shop in Wukari, Nigeria.

\section{Determination of chemical constituents of olive oil}

The analysis of the chemical constituents of olive oil was carried out using GC (model No. 7890B) and MS detector (model 5977A). The method of Imo et al. (2018) was used. The conditions were as follows: The GC-MS was equipped with column: Agilent $\mathrm{HP} 5 \mathrm{MS}$ ultra Inert $\left(350^{\circ} \mathrm{C}\right) 30 \mathrm{~m} \times 250$ $\mu \mathrm{m} \times 0.25 \mu \mathrm{m}$. The gas used was Helium with flow: $0.7 \mathrm{ml} / \mathrm{min}$, pressure: $4.4867 \mathrm{psi}$ and average velocity: $30.641 \mathrm{~cm} /$ seconds. The injection volume used was $1 \mathrm{ml}$ with an inlet temperature of $250^{\circ} \mathrm{C}$, split flow $14 \mathrm{ml} / \mathrm{min}$ and split ratio 20:1. Oven temperature of $60^{\circ} \mathrm{C}$ was used with a $1 \mathrm{~min}$ equilibrating time, maximum oven temperature of $350^{\circ} \mathrm{C}$, and total run time of $35.857 \mathrm{~min}$. The chemical constituents of the olive oil were identified by matching the spectra of the chemical constituent which is to be identified with the mass spectra of reference compound which is contained in the database of National Institute of Standards and Technology (NIST 14). The levels or concentrations of chemicals detected in the olive oil were expressed as area percent which is comparable to the total peak area.

\section{Results and discussion}

Several chemical constituents were detected in olive oil as contained in Table 1. Squalene was the most abundant constituent detected in highest amount, with about $99.56 \%$ of the total constituents detected. Different chemical constituents were detected in olive oil as contained in Table 1 and Fig. 1. Some of the different chemical constituents have been reported to possess various properties and are used for some purposes. Various thiiranes and fused thiiranes have been reported to possess cytotoxic properties. 
The vapours of simple thiirane is reported to possess better disinfecting properties than the oxirane and are also able to destroy Bacterium globigii even at lower concentrations. Thiiranes are also used as antimicrobial (fungicides) and also as insecticides. A thiirane derivative which is known as chlorocyclo propane sulfide is used as a nematocide (Vishnu et al., 2019).

Table 1. Chemical constituents of olive oil.

\begin{tabular}{lll}
\hline Name of compound & Retention time (min) & Area \% \\
\hline Thiirane & 44.74 & 0.00 \\
Ethenamine, N-methylene- & 46.26 & 0.00 \\
Aziridine, 2,2-dimethyl- & 49.63 & 0.06 \\
Acetic acid & 50.52 & 0.00 \\
Formic acid hydrazide & 51.02 & 0.00 \\
Urea & 51.41 & 0.00 \\
Carbonyl sulfide & 54.09 & 0.01 \\
Oxirane, 3-butenyl- & 54.78 & 0.16 \\
sec-Butylamine & 55.21 & 0.02 \\
1-Propanol & 56.10 & 0.00 \\
Propargyl alcohol & 58.04 & 0.00 \\
Cyclopropaneethanol & 58.43 & 0.00 \\
Hydrazine, 1,1-dimethyl- & 59.48 & 0.00 \\
Aminoacetonitrile & 60.17 & 0.00 \\
1,3-Butadiene & 60.95 & 0.01 \\
Azetidine & 61.18 & 0.00 \\
Ethyl isocyanide & 61.84 & 0.00 \\
Silanamine, N-silyl- & 62.07 & 0.00 \\
Chloroacetic acid, 4-tetradecyl ester & 62.23 & 0.00 \\
Propanal, oxime & 63.04 & 0.01 \\
Acetonitrile, 2,2'-iminobis- & 63.31 & 0.01 \\
o-Allylhydroxylamine & 63.62 & 0.01 \\
Glycine, N-acetyl- & 63.89 & 0.01 \\
1,5-Heptadiene, 3-methyl- & 64.17 & 0.00 \\
2-Pentyn-1-ol & 64.32 & 0.00 \\
Cyclobutane, methylene- & 64.52 & 0.00 \\
Ethyl oxamate & 64.79 & 0.00 \\
Squalene & 65.79 & 99.56 \\
Isobutylamine & 66.41 & 0.01 \\
Acetic acid, (aminooxy)- & 66.69 & 0.01 \\
3-Penten-1-ol, (Z)- & 67.19 & 0.01 \\
1-Butanol, 2,2-dimethyl- & 67.35 & 0.00 \\
\hline
\end{tabular}

The presence of thiirane in olive oil shows that olive oil may possess antimicrobial properties and therefore may use used in the production of fungicide, nematocide and insecticide. Carbonyl sulfide was detected in the olive oil and has been reported as a potential alternative fumigant (Bartholomaeus and Haritos, 2005) to methyl bromide and phosphine. This suggest that carbonyl sulfide, if extracted from olive oil may be useful for the production of fumigants. The presence of SecButylamine in olive oil may contribute or promote synergistic effects of thiirane and carbonyl sulfide which are also detected in olive oil. This is because Yoshikawa et al. (1976) has reported that secButylamine at $5 \mathrm{mM}$ inhibited the oxidation of pyruvate by mitochondria isolated from hyphae of 
Penicillium digitatum. Also, Sec-butylamine has been documented as a fumigant fungicide with a high potential for bioaccumulation. It is not approved for fungicidal use in the European Union, however, it has a role as an antifungal agrochemical. It has also been documented as a primary aliphatic amine and an aliphatic nitrogen antifungal agent (ChEBI database).

Abundence

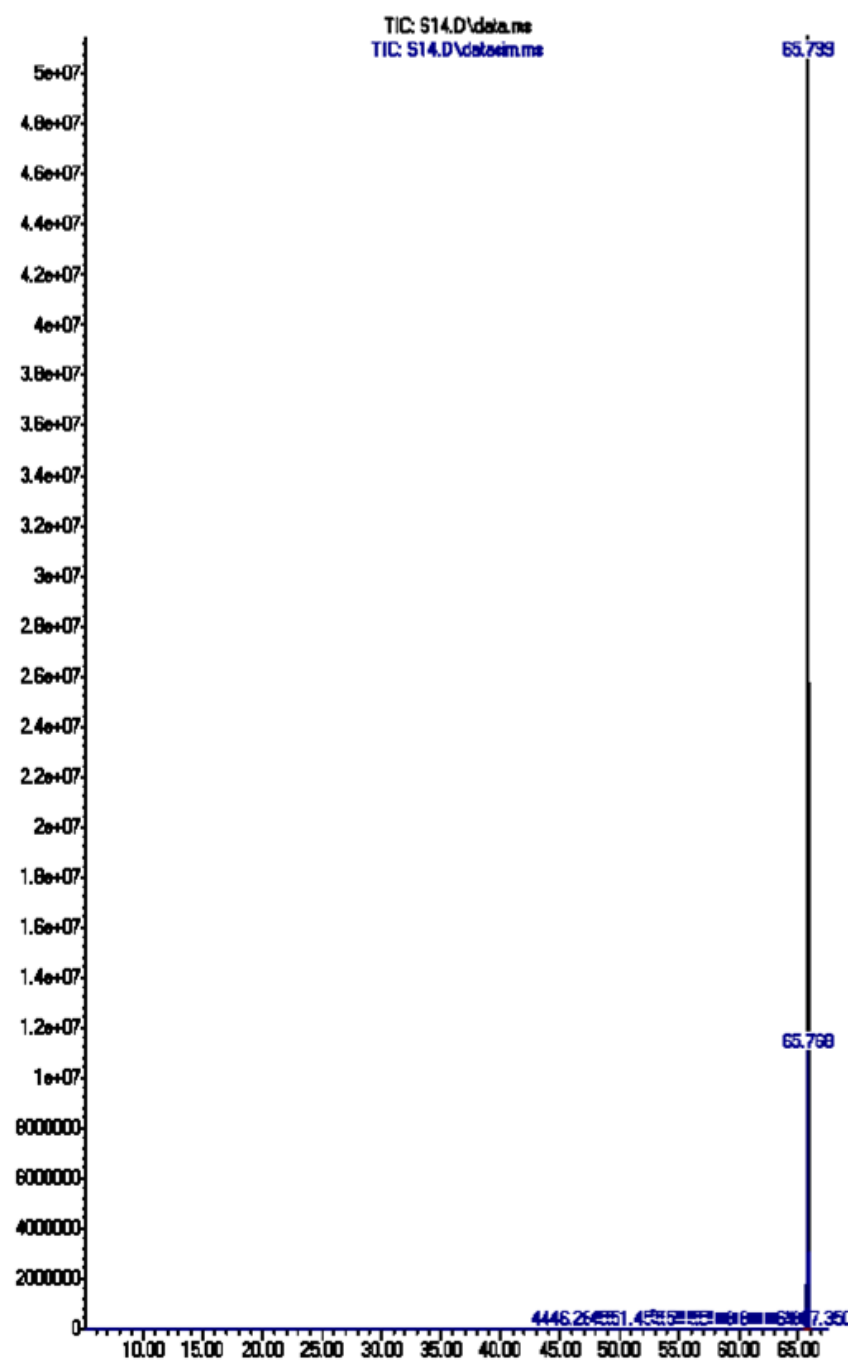

Fig. 1: GCMS chromatogram of olive oil.

Acetic acid is a synthetic carboxylic acid with antibacterial and antifungal properties. Acetic acid, which is a weak acid has the ability to inhibit carbohydrate metabolism resulting in subsequent death of the organism. Acetic acid is also used to dissolve substances needed to make some medicines and other products such as plastics (NCI Thesaurus). It is also used in food canning as an additive or flavoring and in medicines. oAllylhydroxylamine has been reported as a useful intermediate; e.g. cyclization of o-allyloximes to give pyridines (Kusumi et al., 1979). oAllylhydroxylamine has been reported to possess antimicrobial activity against Plasmodium falciparum (Prado-Prado et al., 2010). These functions of acetic acid and o-Allylhydroxylamine corroborate the antimicrobial property of olive oil.

The use of 1-propanol is as a multi-purpose solvent in industry and in the home. It is used in some products such as cosmetics and lotions, polish and antiseptic formulations. This property may support the reason why some people add olive oil to their body cream, since it may be used in lotions. Urea was detected in olive oil and has also been studied as a diuretic. Urea was reported to be used in the treatment of euvolemic hyponatremia and was reported to be safe, inexpensive and simple (Decaux et al., 2010). This suggests olive oil may be needful in the treatment of hyponatremia.

1,3-Butadiene is said to be important industrially as a monomer in the production of synthetic rubber. Propargyl alcohol has a geranium-like odour and has been reported to be used for making other chemicals, as a soil fumigant and a corrosion inhibitor, while Ethyl isocyanate is used for pesticide intermediate and pharmaceutical (Lewis, 2001). Methyl isocyanate is used as a chemical intermediate for the production of carbamate insecticides and herbicides. Chloroacetic acid is reported to be used in the production of drugs, dyes, and pesticides (Koenig et al., 2005).

The antidote of chloroacetic acid poisoning is sodium dichloroacetate $(50 \mathrm{mg} / \mathrm{kg}$ IV over 10 mins, repeated in 2h; double dosage if hemodialysis is performed) (Régnier et al., 1996). The functions of these constituents detected in olive oil suggest that olive oil may be used in some industries for the production of certain pesticides and other chemicals.

Formic hydrazide was reported to be used in the synthesis of 1,2,4-triazole derivatives (Zong et al., 2005) and of new anticancer agent: $6-\mathrm{N}-$ formylamino-12,13-dihydro-1,11-dihydroxy-13- $(\beta$ $D$-glucopyranosyl)-5H-indolo[2,3- $a$ ] pyrrolo [3,4c] carbazole-5,7 $(6 H)$-dione (Ohkubo et al., 1997). The aminoacetonitrile can be hydrolysed to give 
glycine (Pollak et al., 2002). Being bifunctional, it is reported to be useful in the synthesis of diverse nitrogen-containing heterocycles (Tauber and Opatz, 2015). Derivatives of aminoacetonitrile are useful anthelmintic and are reported to act as nematode specific ACh agonists (Kaminsky et al., 2008) causing a spastic paralysis and rapid expulsion from the host. Aminooxyacetic acid has been studied as a treatment for tinnitus. One study showed that about $20 \%$ of patients with tinnitus had a decrease in its severity when treated with aminooxyacetic acid. However, about $70 \%$ of those patients reported side effects which were mostly nausea and disequilibrium (Guth et al., 1990).

Aminooxyacetic acid also has anticonvulsant properties (Davanzo et al., 1961). When given at high dosages, it can act as a convulsant agent in mice and rats (Wood and Peesker, 1973). Aminooxyacetic acid also inhibits aspartate aminotransferase which is an important part of malate-aspartate shuttle (Kauppinen et al., 1987). This inhibition of the malate-aspartate shuttle prevents the reoxidation of cytosolic NADH by the mitochondria in the nerve terminals (Kauppinen et al., 1987). These properties suggest that olive oil may be beneficial as an anticancer, anthelmintic and anticonvulsant. However, it is important that the efficacy of olive oil regarding these claims be validated to ascertain the dose at which it may exert the acclaimed properties.

2-Pentyn-1-ol was employed as starting reagent for the synthesis of (-)-muricatacin (Makabe et al., 1993). Isobutylamine has been reported as an odourant binding to TAAR 3 in mice and can trigger sexual behaviour in male mice dependent on the cluster of TAAR2 through TAAR9 (Harmeier et al., 2018). N-acetylglycine is used in biological research of peptidomimetics and used as the blocking agent of the $\mathrm{N}$-terminus to prepare unnatural and unusual amino acids and amino acid analogs as well as to modify peptides. The NSubstituted glycine analogs are used in peptidomimetics and in drug research (Human Metabolome Database). This suggest the importance of olive oil in biological and drug research.

Squalene is the major constituent detected in highest amount in the olive oil (Table 1 and Fig. 1).
It constitutes about $99.56 \%$ of the constituents detected. Squalene has been reported to be the biochemical precursor to the whole family of steroids (Bloch, 1983). It is known that all plants and animals produce squalene as a biochemical intermediate. As a common lipid produced by sebaceous glands, squalene is known to have a role in topical skin protection and lubrication (Pappas, 2009). Toxicology study indicated that for the concentrations of squalene used in cosmetics, it has low acute toxicity, and it is not a significant contact allergen or irritant (Huang et al., 2009). Squalene is reported not to be very susceptible to peroxidation and appears to function in the skin as a quencher of singlet oxygen, protecting human skin surface from lipid peroxidation due to exposure to UV and other sources of ionizing radiation (Kelly, 1999). Since squalene is the major constituent of olive oil, it therefore means that olive oil will be very useful in skin protection and lubrication.

Squalene has a higher affinity for un-ionized drugs because it is a nonpolar substance. In animals, it has been reported that supplementation of diet with squalene may reduce cholesterol and triglyceride levels (Kelly, 1999). This claim on reduction of cholesterol level is in agreement with the report of Imo and Sunday (2020) who reported a non-significant reduction in total cholesterol level in albino rats administered olive oil when compared with normal rats. In mice, combining squalene with astaxanthin which is an antioxidant lead to higher activation of antioxidant enzymes (SOD1, GPX1) compared to giving either substance alone. This suggests that the combination of squalene with other antioxidants may increase its antioxidant benefits (Ravi et al., 2016).

In human skin cells, squalene has been reported to scavenged free radicals and reduced damage caused by oxidative stress (Kohnoa et al., 1995). This suggests olive oil as a good source of antioxidant and will be good in scavenging free radicals. However, squalene added to vaccines may be linked to a number of side effects (Ahmed et al., 2016). Therefore, it is possible that direct injection of squalene, even with the other potential benefits that it may play in vaccinations may still lead to negative effects. This warrants caution in the use of squalene or even olive oil to avoid its reported negative effects. 


\section{Conclusion}

Several constituents with various functions were detected in olive oil, including squalene. The most abundant constituent detected in highest amount in olive oil was squalene and constitutes about $99.56 \%$ of the total constituents. Squalene may play various roles, including as a good antioxidant. Some of the chemical constituents detected in olive oil have been reported to be used for various purposes, including nutritional, medicinal, pharma-ceutical and industrial. Olive oil is recommended for nutritional, pharmaceutical and medicinal purposes.

\section{Conflict of interest statement}

Authors declare that they have no conflict of interest.

\section{References}

Ahmed, S.S, Montomoli, E., Pasini, F.L., Steinman, L. (2016). The Safety of Adjuvanted Vaccines Revisited: Vaccine-Induced Narcolepsy. Isr Med Assoc J., 18(3-4): 216-220.

Bartholomaeus, A., Haritos, V. (2005). Review of the toxicology of carbonyl sulfide, a new grain fumigant. Food and Chemical Toxicology. 43(12): 1687-1701. DOI: 10.1016/j.fct.2005.06.016.

Bloch, K.E. (1983). Sterol, Structure and Membrane Functio. Critical Reviews in Biochemistry and Molecular Biology, 14: 4792.

Chemical Entities of Biological Interest (ChEBI). URL: http://www.ebi.ac.uk/chebi/search Id.do?chebiId=CHEBI:74526.

Davanzo, J., Greig, M., Cronin, M. (1961). Anticonvulsant properties of amino-oxyacetic acid. American Journal of Physiology, 201: 833-837.

Decaux, G., Andres, C., Gankam, K.F., Soupart, A. (2010). Treatment of euvolemic hyponatremia in the intensive care unit by urea. Critical Care, 14(5): R184. DOI: $10.1186 /$ cc9292.

Fedeli, E. (1977). Lipids of Olives. Prog. Chem. Fats Other Lipids, 15: 57-74.

Fedeli, E. (1993). Olive Oil Technology. Olivae, 45:20-23.

Fito, M., Cladellas, M., de la Torre, R., Marti, J., Alcantara, M., Pujadas-Bastardes, M.,
Marrugat, J. (2005). Antioxidant effect of virgin olive oil in patients with stable coronary heart disease: a randomized, crossover, controlled, clinical trial. Atherosclerosis, 181(1): 149-158.

Grosso, G., Marventano, S., Yang, J., Micek, A., Pajak, A., Scalfi, L., Galvano, F. (2015). A Comprehensive Meta-analysis on Evidence of Mediterranean Diet and Cardiovascular Disease: Are Individual Components Equal? Crit Rev Food Sci Nutr., DOI: 10.1080/10408398.2015.1107021.

Guasch-Ferre, M., Hruby, A., Salas-Salvado, J., Martinez-Gonzalez, M.A., Sun, Q., Willett, W.C., Hu, F.B.. (2015). Olive oil consumption and risk of type 2 diabetes in US women. Am J Clin Nutr., 102(2): 479-486.

Guth, P., Risey, J., Briner, W., Blair, P., Reed, H., Bryant, G., Norris, C., Housley, G., Miller, R. (1990). Evaluation of amino-oxyacetic acid as a palliative in tinnitus. The Annals of Otology, Rhinology, and Laryngology, 99(1): 74-79.

Harmeier, A., Meyer, C.A., Staempfli, A., Casagrande, F., Petrinovic, M.M., Zhang, Y.P., Künnecke, B., Iglesias, A., Höner, O.P., Hoener, M.C. (2018). How Female Mice Attract Males: A Urinary Volatile Amine Activates a Trace Amine-Associated Receptor That Induces Male Sexual Interest. Frontiers in Pharmacology, 9: 924. DOI: 10.3389/fphar.2018.00924.

Huang, Z., Lin, Y., Fang, J. (2009). Biological and Pharmacological Activities of Squalene and Related Compounds: Potential Uses in Cosmetic Dermatology. Molecules, 14(1): 540554.

Human Metabolome Database. URL: http://www.hmdb.ca/metabolites/HMDBooo 0532.

Imo, C., Sunday, O.D. (2020). Comparative Effects of Palm Kernel Oil, Olive Oil, Crude Oil and Honey on Lipid Profile, Body Weight and Hearts of Male Albino Rats. European Journal of Biomedical and Pharmaceutical Sciences, 7(5): 84-90.

Imo, C., Yakubu, O.E., Imo, N.G., Udegbunam, I.S., Onukwugha, O.J. (2018). Chemical composition of Xylopia aethiopica fruits. American Journal of Physiology, Biochemistry and Pharmacology, 7(2): 48-53.

Inglese, P. (1994). Influence of Variety on the Quality Characteristics of Olive Oil. Olivae, 54: 42-47. 
Kaminsky, R., Ducray, P., Jung, M., Clover, R., Rufener, L., Bouvier, J., Weber, S.S., Wenger, A., Wieland-Berghausen, S. (2008). A new class of anthelmintics effective against drugresistant nematodes. Nature, 452(7184): 176180.

Kauppinen, R.A. Sihra, T.S., Nicholls, D.G. (1987). Aminooxyacetic acid inhibits the malateaspartate shuttle in isolated nerve terminals and prevents the mitochondria from utilizing glycolytic substrates. Biochimica et Biophysica Acta., 930(2): 173-178.

Kelly, G.S. (1999). Squalene and its potential clinical uses. Altern Med Rev., 4(1): 29-36.

Kiritsakis, A.K. (1998). Flavor Components of Olive Oil-A Review. Journal of the American Oil Chemists' Society, 75(6): 673-681.

Koenig, G., Lohmar, E., Rupprich, N. (2005). Chloroacetic Acids. Ullmann's Encyclopedia of Industrial Chemistry. Weinheim: Wiley-VCH. DOI: 10.1002/14356007.a06_537.

Kohnoa Y., Egawab Y., Itohb S., Nagaokab S., Takahashia M., Mukai K. (1995). Kinetic study of quenching reaction of singlet oxygen and scavenging reaction of free radical by squalene in n-butanol. Biochimica et Biophysica Acta (BBA) - Lipids and Lipid Metabolism, 1256(1): 52-56.

Kusumi, T., Yoneda, K., Kakisawa, H. (1979). A Convenient Synthesis of $5,6,7,8$ Tetrahydroquinoline. Synthesis, 221-221, (1979).

Lewis, R.J. Sr. (2001). Hawley's Condensed Chemical Dictionary 14th Edition. John Wiley \& Sons, Inc. New York, NY, pp. 472, 738, 927.

Lopez, S., Bermudez, B., Montserrat-de la Paz, S., Jaramillo, S., Abia, R., Muriana, F.J. (2016). Virgin Olive Oil and Hypertension. Curr Vasc Pharmacol. 14(4): 323-329.

Makabe, H., Tanaka, A., Oritani, T. (1993). Synthesis of (-)-muricatacin. Bioscience, Biotechnology, and Biochemistry, 57(6): 10281029.

NCI Thesaurus. URL: https://ncit.nci.nih.gov/ ncitbrowser/ ConceptReport.jsp?dictionary= NCI_Thesaurus\&ns $=$ NCI_Thesaurus\&code $=\mathrm{C}$ 61623.

Ohkubo, M., Kawamoto, H., Ohno, T., Nakano, M., Morishima, H. (1997). Synthesis of NB-506, a new anticancer agent. Tetrahedron, 53(2), 585592.

Pappas, A. (2009). Epidermal surface lipids.
Dermato-endocrinology, 1(2): 72-76. DOI: 10.4161/derm.1.2.7811.

Pollak, P., Romeder, G., Hagedorn, F., Gelbke, H. (2002). Nitriles. Ullmann's Encyclopedia of Industrial Chemistry. Weinheim: Wiley-VCH. DOI: 10.1002/14356007.a17_363.

Prado-Prado, F.J., García-Mera, X., González-Díaz, H. (2010). Multi-target spectral moment QSAR versus ANN for antiparasitic drugs against different parasite species. Bioorg Med Chem., 18(6): 2225-2231.

Psaltopoulou, T., Kosti, R.I., Haidopoulos, D., Dimopoulos, M., Panagiotakos, D.B. (2011). Olive oil intake is inversely related to cancer prevalence: a systematic review and a metaanalysis of 13,800 patients and 23,340 controls in 19 observational studies. Lipids Health Dis., 10: 127 .

Ranalli, A., Ferante, M.L. (1996). PhysicoChemical and Analytical Characteristics of Extra Virgin Olive Oils Extracted by Using a Pectolytic Enzymatic Processing Aid. Olivae, 60: 27-32.

Ravi, K.S., Narayan, B., Sawada, Y., Hosokawa, M., Miyashita, K. (2016). Combined effect of astaxanthin and squalene on oxidative stress in vivo. Mol Cell Biochem., 417(1-2): 57-65.

Régnier, J.F., et al (1996). Experimental evaluation of potential antidotes for monochloroacetic acid (MCA) acute poisoning. Hum Exp Toxicol., 15: 850.

Sala-Vila, A., Guasch-Ferre, M., Hu, F.B., SanchezTainta, A., Bullo, M., Serra-Mir, M., LopezSabater, C. (2016). Dietary alpha-Linolenic Acid, Marine omega-3 Fatty Acids, and Mortality in a Population With High Fish Consumption: Findings From the PREvencion con DIeta MEDiterranea (PREDIMED) Study. J Am Heart Assoc. 5(1).

Storniolo, C.E., Casillas, R., Bullo, M., Castaner, O., Ros, E., Saez, G.T., Toledo, E. (2015). A Mediterranean diet supplemented with extra virgin olive oil or nuts improves endothelial markers involved in blood pressure control in hypertensive women. Eur J Nutr. DOI: 10.1007/ s00394-015-1060-5.

Tauber, J., Opatz, T. (2015). 2-Aminoacetonitrile. E-EROS Encyclopedia of Reagents for Organic Synthesis: $1-4$.

Vishnu, J.R., Arun, S., Mahendra, N., Ramendra, P. (2019). Three-Membered Ring Heterocycles. In The Chemistry of Heterocycles, pp: 19-92. 
Wood, J., Peesker, S. (1973). The role of GABA metabolism in the convulsant and anticonvulsant actions of aminooxyacetic acid. Journal of Neurochemistry, 20(2): 379-387.

Xin, Y., Li, X.Y., Sun, S.R., Wang, L.X., Huang, T. (2015). Vegetable Oil Intake and Breast Cancer Risk: a Meta-analysis. Asian Pac J Cancer Prev., 16(12): 5125-5135.

Yoshikawa, M., Eckert, J.W., Keen, N.T. (1976). The mechanism of fungistatic action of secbutylamine: II. The effect of sec-butylamine on pyruvate oxidation by mitochondria of Penicillium digitatum and on the pyruvate dehydrogenase complex. Pestic Biochem Physiol., 6(5): 482-490.

Zong, Y., Wang, J., Yue, G., Feng, L., Song, Z., Song, H., Han, Y. (2005). Traceless liquidphase synthesis of 3-alkylamino-4,5disubstituted-1,2,4-triazoles on polyethylene glycol (PEG). Tetrahedron Letters, 46(31): 5139-5141.

\section{How to cite this article:}

Imo, C., 2020. Chemical constituents of olive oil commonly sold in Wukari, Nigeria. Int. J. Curr. Res. Biosci. Plant Biol. 7(6), 37-44. doi: https://doi.org/10.20546/ijcrbp.2020.706.004 